\title{
Bilgisayar navigasyonlu ve robotik kol yardımlı total diz protezi uygulamaları
}

\section{Total knee replacement applications with computer navigation and robotic arm assisted}

\author{
İbrahim Tuncay, Ahmet Can Erdem
}

Bezmialem Vakıf Universitesi Tıp Fakültesi Hastanesi, Ortopedi ve Travmatoloji Ana Bilim Dalı, İstanbul

Total diz protezi (TDP), son evre diz artrozunun cerrahi tedavisinde hastaların yaşam kalitesini ve diz ekleminin fonksiyonelliğini artıran oldukça başarılı bir cerrahidir. Ancak TDP uygulanan hastaların bir kısmı klinik sonuçlarından yeterince memnun değildir. Bilgisayar navigasyonlu ve robot yardımlı TDP uygulamaları, hasta memnuniyetini artırmanın bir yolu olarak artan ilgi ve popülerlik kazanmıştır. Bu tür sistemlerin TDP uygulamalarındaki amacı, cerraha kemik kesilerini ameliyat öncesi planlamaya uygun şekilde yapılmasına olanak sağlamakla birlikte; ideal diz kinematiği ve yumuşak doku dengesini geri kazandırmaya yardımcı olmalarıdır. Bilgisayarlı navigasyon ve robotik kullanımının daha uzun implant sağkalımına ve daha fonksiyonel olduğuna dair kanıtlar artmaktadır.

Anahtar sözcükler: total diz protezi; gonartroz; robotik kol yardımlı cerrahi; navigasyon; artroplasti; diz
Total knee arthroplasty (TKA) is a very effective method in the surgical treatment of advance stage gonarthrosis, that increases the functionality of the knee joints and improves the quality of life of the patients. However, some of the patients who underwent this operation are not satisfied. In recent years, robotic-arm-assisted TKA using computer navigation gained popularity as a way to improve patient satisfaction. This system allows the surgeon to achieve the bone cuts more accurate to preoperative planning and to receive intraoperative feedbacks which contribute to regaining of knee kinematics and soft tissue balance. There is increasing evidence that robotic-arm-assisted TKA with computer navigation leads to prolonged implant survival and improved functional outcomes.

Key words: total knee prosthesis; gonarthrosis; robotic arm assisted surgery; navigation; arthroplasty; knee

.

leri evre diz osteoartritinin tedavisinde uygulanan total diz protezi (TDP), uzun yıllardır uygulanan ve oldukça başarılı sonuçlar elde edilmiş bir yöntemdir. Ancak TDP uygulanan hastaların \%20 kadarı klinik sonuç olarak yeterince memnun değillerdir. ${ }^{[1]}$ Bundan dolayı, son teknolojik gelişmeler, ortopedi ve travmatoloji uzmanlarının TDP uygulamalarını daha doğru ve hassas bir şekilde gerçekleştirmesini hedeflemiştir. Diz kinematiği ve yumuşak doku dengesinin yeniden sağlanabilmesi için, komponentlerin femur ve tibianın mekanik eksenlerine dik olarak uygulanması temel bir ilkedir. ${ }^{[2]}$ Robot yardımlı TDP uygulamalarında, alt ektremite dizilimi, femoral ve tibial komponent yerleşimi ve yumuşak doku dengelemesi ideale yakın olarak gerçekleştirilmektedir. ${ }^{[2]}$ Ayrıca robot yardımlı TDP, konvansiyonel tekniklere kıyasla daha az yumuşak doku hasarına neden olmaktadır. ${ }^{[3]}$

\section{ROBOTIK KOL YARDIMLI TOTAL DIZ PROTEZI UYGULAMA AŞAMALARI}

Robotik kol yardımlı cerrahi ile protez ameliyatına karar verildiğinde, her iki alt ekstremitenin kalçadan ayak bileğine kadar bilgisayarlı tomografisi çekilir. Bunun için özel kesitlerin alınması ve protokollerin uygulanması gerekir. Bu veriler daha sonra bilgisayara yüklenerek her iki alt ekstremitenin üç boyutlu modeli oluşturulur. Ameliyattan birkaç gün önce bilgisayar programı ile adım adım cerrahi planlanır. Diz protezi yapılacak ise kemik kesilerinin kalınlığı, bağ dengesi, protezin en uygun boyutu ve yerleştirilme açısı önceden planlanır.

Ameliyat sırasında, femur distali ve tibia proksimaline "array" adı verilen alıcılar yerleştirilir (Şekil 1). Bu cihazlar, bilgisayara anlık olarak kemiklerin uzaydaki pozisyonunu bildirmek için gereklidir. Uygun cerrahi

iletişim / Contact: Öğr. Gör. Dr. Ahmet Can Erdem • E-posta / E-mail: erdem.canahmet@gmail.com

ORCID iD: Ibrahim Tuncay, 0000-0001-5778-692X • Ahmet Can Erdem, 0000-0002-4763-1112

Geliş / Received: 12 Temmuz 2021 • Kabul / Accepted: 22 Temmuz 2021 


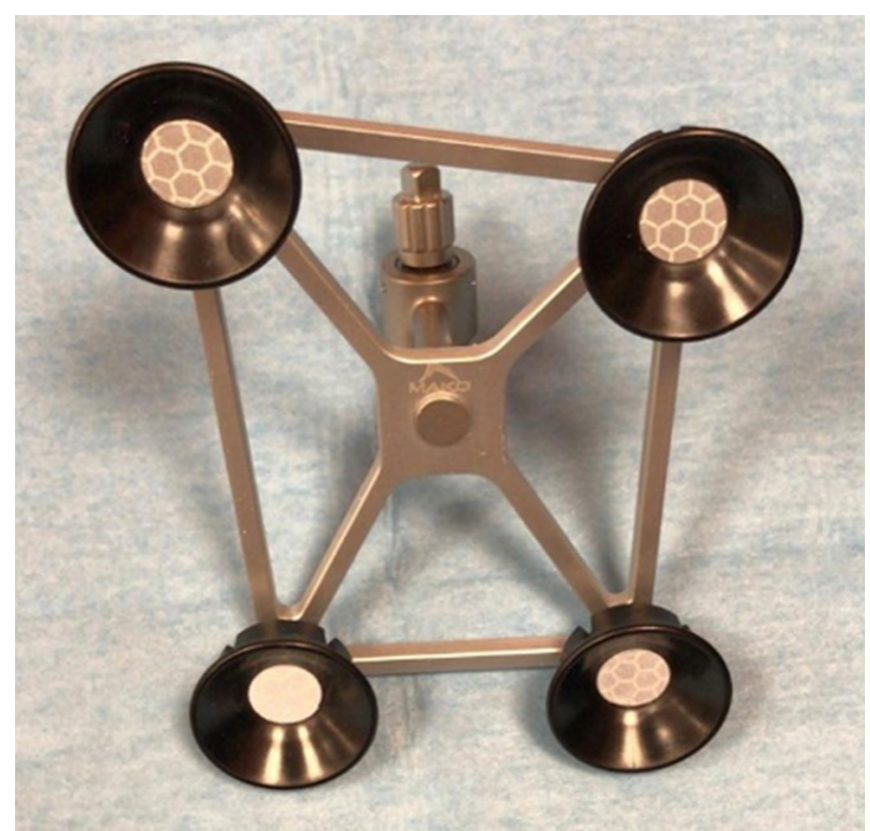

Şekil 1. Array.

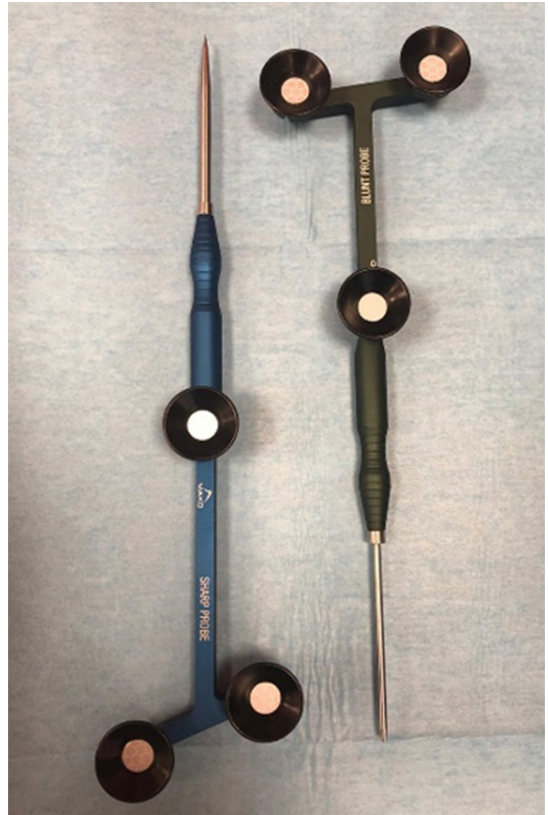

Şekil 2. Elektronik kalem. açılım yapıldıktan sonra, elektronik kalem şeklinde bir cihazla kemiklerin haritası çıkartılır ve bilgisayara tanıtılır (Şekil 2). Bilgisayar, bu haritayı ameliyat öncesi çekilen tomografi kesitleri ile eşleştirir. Böylece artık robotik sisteme, kemiğin hangi bölgesinden ne kadar kesi yapacağı tanımlanmış olunur. Bu sırada eklem çevresi bağlar da test edilerek en uygun bağ dengesi sağlanacak şekilde kesiler yeniden hesaplanır.

Robotik kol yardımıyla kemik kesileri uygun açı ve doğrultuda kesilir. Sistem kesiler sırasında sadece önceden planlanan alanlar içerisinde çalışır ve bu alanların dışına çıkılmasına izin verilmez. Böylece daha fazla yumuşak doku hasarının önüne geçilmiş olunur. Cerrah ameliyat sırasında bütün bu aşamaları hem ameliyat bölgesini gözleyerek, hem de bilgisayar ekranında üç boyutlu olarak kontrol ederek gerçekleştirir (Şekil 3).

Tüm kemik kesileri tamamlandıktan sonra, deneme protezleri yerleştirilir ve robotik sistem ile tekrar kontrol edilir. Bu sırada yumuşak doku dengesi, bağların gerginliği ve dizilimin uygunluğu doğrulanır. Gerekirse tekrar milimetrik düzeltmeler yapılabilir. Cerrah yapılan ölçümleri onaylar ise sıra komponentlerin yerleştirilmesine gelinir. Femoral ve tibial komponentler yerleştirildikten sonra, son aşamada eklem hareket açıklığı ve bağ dengesi kontrol edilerek ameliyata son verilir.

\section{ROBOTIK KOL YARDIMLI TOTAL DIZ PROTEZI UYGULAMALARININ AVANTAJ VE DEZAVANTAJLARI}

Robotik kol yardımlı protez cerrahisinin en önemli avantajı, ameliyatın gözle görülenden çok daha hassas bir şekilde yapılmasını sağlamasıdır. ${ }^{[4-7]}$ Ameliyatın tamamı, işlemden önce milimetrik olarak planlanır ve ameliyat sırasında robotik kol ise bu planın en hassas şekilde uygulanmasını sağlar. ${ }^{[8,9]}$ İstendiğinde ameliyat sırasında yapılan ölçümlerle bu plan değiştirilebilir. Özellikle ameliyat sonrası protezin uzun ömürlü olması ve hasta memnuniyetinin yüksek olması için, komponent yerleşimi, dizilimi ve yumuşak doku dengesinin ideal ölçülerde sağlanmış olması çok önemlidir. ${ }^{[4,6]}$ Robotik kol yardımlı cerrahi bu hedeflere en az hata ile ulaşılmasını sağlayan bir yardımcıdır. Avantajları arasında implant pozisyonunda artan doğruluk, potansiyel olarak daha az komplikasyon ve iyileştirilmiş implant pozisyonuna bağlı olarak daha iyi klinik fonksiyon ve implant sağkalımı yer alır. ${ }^{[6,7]}$ Özellikle bazı çalışmalarda alt ekstremite diziliminin robot yardımlı gruplarda daha ideale yakın olduğu gösterilmiştir.

\section{Doğruluk ve Hassasiyet}

Hampp ve ark.'nın yaptığı kadavra çalışmasında, altı dize robotik kol yardımlı TDP, diğer altı dize ise konvansiyonel yöntem ile TDP uygulanmış. Daha sonra ameliyat öncesi planlamaya göre komponentlerin yerleşimine 


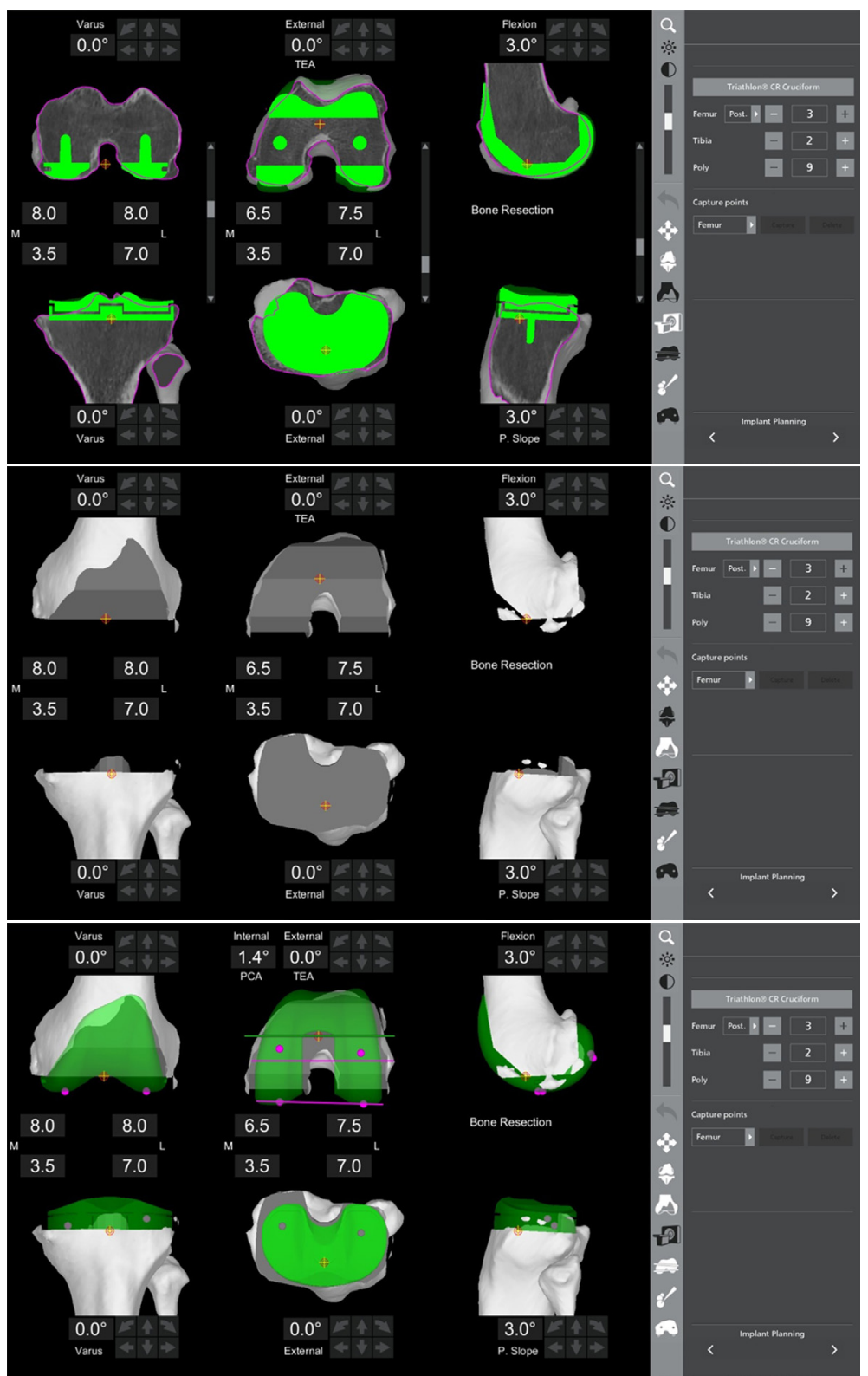

Şekil 3. Bilgisayar ortamında uygun kesilerin yapılması ve uygulanacak protezin ölçülerinin belirlenmesi.

bakılmış. Konvansiyonel yöntemle uygulanan TDP’lerle karşılaştırıldığında, robotik kol yardımlı TDP uygulanmasında kemik kesimlerinin daha doğru (12 kemik kesim ölçümünün 11'i) ve planlama açısından daha uygun (tüm kemik kesim ölçümleri) olduğu görülmüştür. ${ }^{[8]}$

Marchand ve ark., robotik kol yardımlı TDP uygulanan 330 hastanın ameliyat öncesi ve ameliyat sonrası koronal dizilimini değerlendirmişler. Ameliyat öncesi hastaların $\% 64$ 'ünde $3^{\circ}$ 'den fazla varus ve $\% 11$ 'inde ise $3^{\circ}$ 'den fazla valgus deformitesi tespit edilmiştir.
Başlangıç deformitesi $7^{\circ}$ veya daha az varusu olan tüm hastaların nötral olarak düzeltildiği, $3^{\circ}$ 'den fazla valgus deformitesi olanların \%96'sının da ameliyat sonrası nötral olduğu tespit edilmiştir. ${ }^{[9]}$

2019'da Ren ve ark.'nın derlemesinde, yedi çalışma ve TDP uygulanan 517 hasta değerlendirilmiş. Konvansiyonel cerrahi ile karşılaştırıldığında, robotik yardımlı TDP uygulanan hastaların daha iyi alt ektremite dizilimi ve daha uygun implant pozisyonunda olduğu görülmüştür. Ayrıca daha iyi fonksiyonel skor 
(Western Ontario ve McMaster University, Knee Society Score fonksiyonel skoru) ve daha az drenaj istatistiksel olarak anlamlı görülmüştür. Ameliyat süresi, eklem hareket açıklığı ve komplikasyon oranları karşılaştırıldığında anlamlı bir farklııık olmadığı bildirilmiştir. [10]

Daha birçok çalışmada, robotik kol yardımlı TDP yapılan hastaların konvansiyonel yönteme göre komponent yerleşimi ve kemik kesilerinin doğruluğunun daha iyi olduğu gösterilmiştir.

\section{Yumuşak Doku Korunması}

Robotik kol yardımlı TDP'leri değerlendiren birkaç çalışma, konvansiyonel tekniğe benzer komplikasyon oranları bildirmiştir. ${ }^{[11-13]}$ Yumuşak doku korunmasının karşılaştırıldığı kadavra modelinde altı dize robotik yöntem ile, altı dize ise konvansiyonel yöntem ile TDP uygulanmış. Daha sonra bağımsız bir ortopedi ve travmatoloji uzmanı, bağ ve yumuşak doku yaralanması açısından kadavra dizlerinin görsel muayenesini gerçekleştirmiş. Robotik kol yardımlı kesileri yapılan dizlerde, iç ve dış yan bağların bütünlügünü koruduğu ayrıca arka çapraz bağı koruyan bir kemik köprüsüne sahip olduğu görülmüştür. Konvansiyonel kesileri yapılan, altı kadavra dizin ikisinde arka çapraz bağda (AÇB) kısmi yaralanma olduğu görülmüştür. Robotik kol yardımlı TDP'de bağ yaralanmasının olmamasının nedeni; bıçak belirlenen alanın dışına çıktığında (kemik korteksleri veya AÇB kemik köprüsü gibi), robotik kol kapanır ve geri çekilir. Ayrıca robotik yardımlı TDP işlemlerin hiçbirinde tibial subluksasyon ve patellar eversiyona ihtiyaç duyulmadığı için daha az yumuşak doku hasarına neden olduğu görülmüştür. ${ }^{[3]}$

Siebert ve ark., robotik kol yardımlı TDP uygulanan 70 hasta ile konvansiyonel TDP uygulanan 50 hastayı geriye dönük olarak değerlendirmişler. Robotik grupta yumuşak doku şişliğinin daha az olduğu ve hiçbir yumuşak doku komplikasyonu olmadığı bildirilmiştir. ${ }^{[14]}$

Yukarıdaki bulguları doğrulamak için daha geniş, ileriye dönük, randomize çalışmalara ihtiyaç vardır. Bununla birlikte mevcut literatür, robotik kol yardımlı TDP ile konvansiyonel TDP karşılaştırıldığında eşdeğer veya daha üstün yumuşak doku koruması sağladığı göstermiş̧tir. ${ }^{[3]}$

\section{Hasta Memnuniyeti}

Hasta memnuniyeti ile ilgili Marchand ve ark., ağrı, fiziksel işlev ve toplam hasta memnuniyeti gibi parametreler ile 20 robotik kol yardımlı TDP hastasını, 20 konvansiyonel TDP hastası ile karşılaştırmışlardır. Her iki gruptaki hastalara erken hareket ve fizik tedaviyi içeren benzer ameliyat sonrası rehabilitasyon uygulanmıştır. Hastalar altı ay takip edilmiştir. Altı ay sonunda robotik kol yardımlı TDP uygulanan hastalarda anlamlı olarak daha düşük ortalama ağrı skorları ve daha iyi genel memnuniyet tespit edilmiştir. ${ }^{[11]}$

Liow ve ark., SF-36 yaşam kalitesi ölçüsünü kullanarak 31 robotik kol yardımlı TDP ile 29 konvansiyonel TDP'yi karşılaştıran randomize, kontrollü bir çalışma gerçekleştirmişlerdir. Robotik kol yardımlı TDP uygulanan hastaların daha iyi yaşam gücüne sahip olduğu tespit edilmiştir. ${ }^{[15]}$

Bu çalışmalar değerlendirildiğinde, robotik kol destekli TDP uygulamaları hasta memnuniyetini ve sonuçlarını iyileştirmeye yardımcı olabilir.

\section{Öğrenme Eğrisi}

Robotik kol yardımlı TDP uygulamaları kısa öğrenme eğrisine sahip olup, bu sayede cerrahın kısa sürede optimum klinik ve radyolojik sonuçlara ulaşmasını sağlamaktadır. ${ }^{[16,17]}$ Sodhi ve ark.'na ait klinik bir çalışmada, özellikle daha önce robotik kol yardımlı TDP deneyimi olmayan iki cerrah seçilmiş ve bu iki cerrahın 240 hastaya robotik kol yardımlı TDP uygulama süreleri analiz edilmiştir. Bu 240 hasta içerisinden; her iki cerrahın da robotik kol yardımlı TDP uyguladığı ilk 20 hasta ve son 20 hastanın ameliyat sürelerinin ortalamaları ile yine bu cerrahlar tarafindan konvansiyonel TDP uygulanan 20 hastanın ameliyat süreleri kıyaslanmıştır. Buna göre, Cerrah 1'in ilk 20 hastasının ortalama süresi 81 dakika, son 20 hastasının ortalama süresi 70 dakika, konvansiyonel TDP uyguladığı 20 hastasının ortalama süresi 68 dakika olduğu görülmüştür. Cerrah 2'nin ilk 20 hastasının ortalama süresi 117 dakika, son 20 hastasının ortalama süresi 98 dakika, konvansiyonel TDP uyguladığı 20 hastasının ortalama süresi 95 dakika olduğu görülmüştür. Her iki cerrah içinde robotik kol yardımlı TDP uygulanan son 20 hasta ile konvansiyonel TDP uygulanan 20 hasta arasında ameliyat süresi açısından anlamlı fark saptanmamıştır. ${ }^{[16]}$

Benzer şekilde, Liow ve ark., 31 robotik ve 29 konvansiyonel TDP uygulanan hastaları kıyaslamışlar ve ortalama ameliyat sürelerinin her iki grupta da benzer olduğu görülmüştür (91'e karşı 93 dakika). [13]

Yine 2019 yılında Jeon ve ark.'nın yapmış olduğu ve ortalama 10 yıllık takiplerinin olduğu geriye dönük çalışmada da komplikasyon ve revizyon cerrahisi oranlarında robotik yardımlı ile konvansiyonel uygulanan total diz protezi grupları arasında anlamlı fark görülmediği bildirilmiştir. ${ }^{[18]}$ Robot yardımlı artroplasti ameliyatlarında cerrahi sürenin bir miktar daha uzun olduğunu bildiren çalışmalar ${ }^{[19]}$ olduğu gibi öğrenme eğrisinin bu konuda önemli olduğunu ve öğrenme eğrisi tamamlandığında cerrahi 
süredeki farkın kalmadığını bildiren çalışmalar da literatürde bulunmaktadır. ${ }^{[20]}$ Aynı çalışmada ayrıca öğrenme eğrisinin komponent diziliminde etkili olmadığı belirtilmiş olup öğrenme eğrisi tamamlanmasa bile ideal komponent diziliminin sağlandığı bildirilmiştir. ${ }^{[17,19,20]}$

Tibia veya femurda ekstra-artiküler deformiteleri olan hastalarda, başarılı bir total diz protezi sonuçları için optimal mekanik eksen hizalamasına ulaşmak gerekmektedir. Bu eklem dışı deformitelerin varlığında standart ameliyat teknikleri ve aletleri ile yeterli olmayabilir. Eklem dışı deformitesi olan hastalarda TDP'nin en iyi nasıl uygulanabileceğine ilişkin karar, kapsamlı bir hasta öyküsü, fizik muayene ve deformitenin diz eklemine yakınlığının ve büyüklüğünün ayrıntılı bir şekilde değerlendirmesi gerekmektedir. Robotik cerrahide ameliyat öncesi tüm alt ekstremitenin bilgisayarlı tomografisinin çekilmesi ile üç boyutlu planlaması yapılabilir; böylece ameliyat öncesi deformitenin uygun bir şekilde değerlendirilmesine, dengeli ve dizilimi uygun bir total diz protezi uygulanmasına yardımcı olur. ${ }^{[21]}$

Kliniğimizde femur ekstra-artiküler deformitesi olan iki hastaya robotik kol yardımlı TDP uygulanmıştır. Hastalarımızdan birinin ateşli silah yaralanması sonucu femurunda koronal ve sagittal deformitesi mevcuttu. Bu deformitelerde intramedüller sistemler kullanılamayacağı için, tüm alt ekstremitenin bilgisayarlı tomografisi çekilerek robotik sisteme aktarıldı ve en uygun alt ekstremite dizilimi sağlayacak şekilde implantlar yerleştirildi (Şekil 4).

Robotik kol yardımlı artroplastinin sorunlarından biri de konvansiyonel protez cerrahisine göre daha pahalı olmasıdır. Bu konuda yapılmış çalışmalar $\mathrm{da}^{[22]}$ bunu göstermiş olup fiyat-etkinlik oranı açısından literatürde yapılmış kanıt düzeyi yüksek çalışma bulunmamaktadır. Ayrıca robotik cerrahide kemiklere 'array' adı verilen sensörler yerleştirilmekte olup ekstra kemik girişinin olması kırık ya da enfeksiyon açısından riskli olabileceği konusunda tartışmaya neden olmaktadır. Bu konuda literatürde gösterilebilecek kanıt düzeyi yüksek çalışma olmamakla birlikte, robotik cerrahinin eleştirilen taraflarındandır. ${ }^{[1,11,15]}$

Literatürde yapılmış çalışmalar genellikle orta dönem sonuçlar bildirmektedir. Robotik cerrahi teknolojisinin gelişmesi ile birlikte eleştirilen taraflarının azalacağını, ideal bağ dengesi ve uygun komponent dizilimi sayesinde uzun dönem sağkalımı çok fazla artıracağını düşünmekteyiz. Teknolojik gelişmelerin yakından takip edilmesi gerektiğini ve ortopedik cerrahinin geleceğinde çok önemli bir yere sahip olacağını öngörmekteyiz.
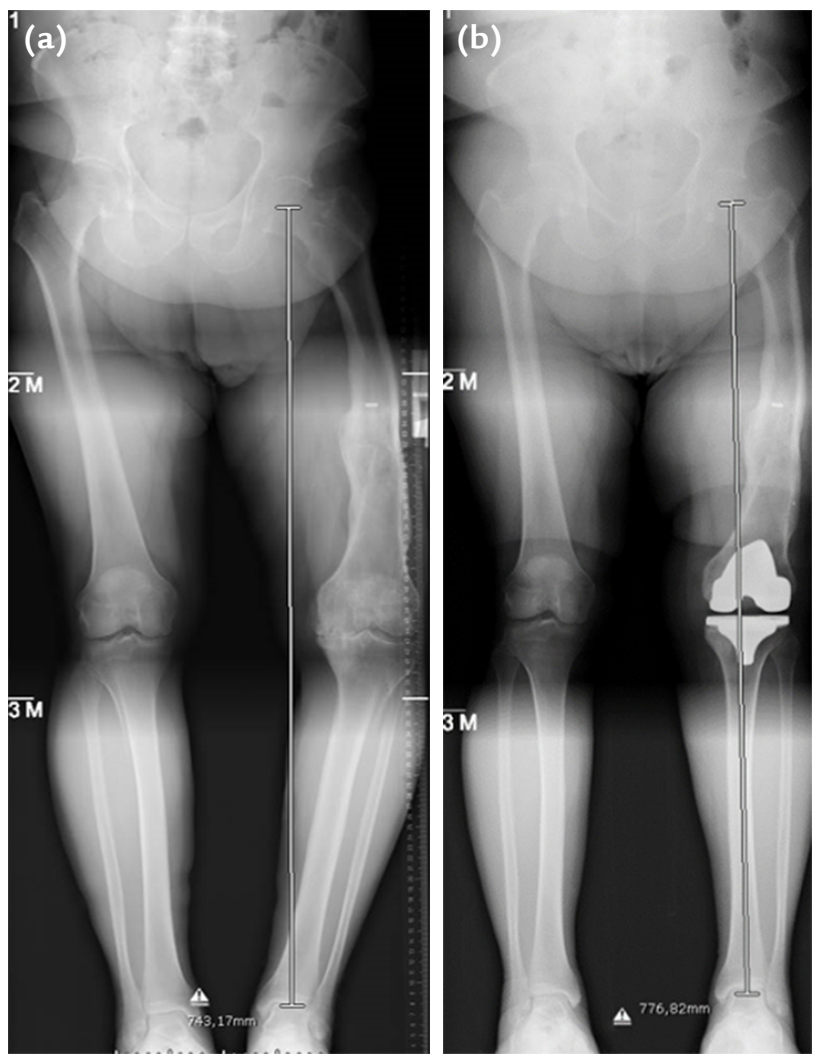

Şekil 4. a, b. Hastanın ameliyat öncesi (a) ve ameliyat sonrası (b) ortoröntgenografileri.

\section{KAYNAKLAR}

1. Bautista M, Manrique J, Hozack WJ. Robotics in Total Knee Arthroplasty. J Knee Surg 2019;32(7):600-6. Crossref

2. Mathew KK, Marchand KB, Tarazi JM, Salem HS, DeGouveia W, EhioroboJO, Sodhi N, Mont MA. Computer-Assisted Navigation in Total Knee Arthroplasty. Surg Technol Int 2020;36:323-30. https://pubmed.ncbi.nlm.nih.gov/32294224/

3. Khlopas A, Chughtai M, Hampp EL, Scholl LY, Prieto M, Chang T-C, Abbasi A, Bhowmik-Stoker M, Otto J, Jacofsky DJ, Mont MA. Robotic-arm Assisted Total Knee Athroplasty Demonstrated Soft Tissue Protection. Surg Technol Int 2017;30:441-6. https:// pubmed.ncbi.nlm.nih.gov/28696495/

4. Khlopas A, Sodhi N, Sultan AA, Chughtai M, Molloy RM, Mont MA. Robotic Arm-Assisted Total Knee Arthroplasty. J Arthroplasty 2018;33(7):2002-6. Crossref

5. Batailler C, Fernandez A, Swan J, Servien E, Haddad FS, Catani F, Lustig S. MACO CT-based robotic arm-assisted system is a reliable procedure for total knee arthroplasty: a systematic review. Knee Surg Sports Traumatol Arthrosc 2020. Crossref

6. Smith AF, Eccles CJ, Bhimani SJ, Denehy KM, Bhimani RB, Smith LS, Malkani AL. Improved Patient Satisfaction Following Robotic-Assisted Total Knee Arthroplasty. J Knee Surg 2021;34(7):730-8. Published online: 15 November 2019. https://dynamix-cdn.s3.amazonaws.com/bluegrassorthocom/ bluegrassorthocom_124081629.pdf Crossref

7. Urish KL, Conditt M, Roche M, Rubash HE. Robotic Total Knee Arthroplasty: Surgical Assistant for a Customized Normal Kinematic Knee. Orthopedics 2016;1;39(5):e822-7. Crossref 
8. Hampp EL, Chughtai M, Scholl LY, Sodhi N, Bhowmik-Stoker M, Jacofsky D, Mont M. Robotic-arm Assisted Total Knee Arthroplasty Demostrated Greater Accuracy and Prencision to Plan Compared to Manuel Technique. J Knee Surg 2019;32(3):239-50. Crossref

9. Marchand RC, Sodhi N, Khlopas A, Sultan AA, Higuera CA, Stearns KL, Mont MA. Coronal correction for severe deformity using robotic-assisted total knee arthroplasty. J Knee Surg 2018;31(1):2-5. Crossref

10. Ren $Y$, Cao S, Wu j, Weng X, Feng B. Efficacy and Reliability of Active Robotic-Assisted Total Knee Arthroplasty Compared With Conventional Total Knee Arthroplasty: A Systematic Review and Meta-Analysis. Postgrad Med J 2019;95:125-33. Crossref

11. Marchand RC, Sodhi N, Khlopas A, Sultan AA, Harwin SF, Malkani AL, Mont MA. Patient Satisfaction Outcomes after Robotic Arm-Assisted Total Knee Arthroplasty: A Short-Term Evaluation. J Knee Surg 2017;30(9):849-53. Crossref

12. Marchand RC, Sodhi N, Anis HK, Ehiorobo J, Newman JM, Taylor K, Condrey C, Hepinstall MS, Mont MA. One-Year Patient Outcomes for Robotic-Arm-Assisted versus Manual Total Knee Arthroplasty. J Knee Surg 2019;32(11):1063-8. Crossref

13. Liow MHL, Xia Z, Wong MK, Tay KJ, Yeo SJ, Chin PL. Robotassisted total knee arthroplasty accurately restores the joint line and mechanical axis. A prospective randomise study. J Arthroplasty 2014;29(12):2373-7. Crossref

14. Siebert W, Mai S, Kober R, Heeckt PF. Technique and First Clinical Results of Robot-assisted Total Knee Replacement. Knee 2002;9(3):173-80. Crossref

15. Liow MHL, Goh GS-H, Wong MK, Chin PL, Tay DK-J, Yeo S-J. Robotic-assisted total knee arthroplasty may lead to improvement in quality-of-life measures: a 2- year followup of a prospective randomized trial. Knee Surg Sports Traumatol Arthrosc 2017;25(9):2942-51. Crossref
16. Sodhi N, Khlopas A, Piuzzi NS, Sultan AA, Marchand RC, Malkani AL, Mont MA. The learning curve associated with robotic total knee arthroplasty. J Knee Surg 2018;31(1):1721. Crossref

17. Marchand KB, Ehiorobo J, Mathew KK, Marchand RC, Mont MA. Learning Curve of Robotic-Assisted Total Knee Arthroplasty for a High-Volume Surgeon. J Knee Surg 2020. Crossref

18. Jeon S-W, Kim K-I, Song SJ. Robot-Assisted Total Knee Arthroplasty Does Not Improve Long-Term Clinical and Radiologic Outcomes. J Arthroplasty 2019;34(8):1656-61. Crossref

19. Zhang G-H, Li K, Zhao B, Zhang Y-W, Wang Y, Zhang Z-L. Clinical effects of robot-assisted total knee arthroplasty compared with traditional surgery: a Meta-analysis. Zhongguo Gu Shang 2019;32(9):846-52. Crossref

20. Vermue H, Luyckx T, de Grave PW, Ryckaert A, Cools A-S, Himpe N, Victor J. Robot-assisted total knee arthroplasty is associated with a learning curve for surgical time but not for component alignment, limb alignment and gap balancing. Knee Surg Sports Traumatol Arthrosc 2020. Crossref

21. Sodhi N, Khlopas A, Ehiorobo JO, Condrey C, Marchand K, Marchand RC, Hepinstall MS, Mont MA. Robotic-Assisted Total Knee Arthroplasty in the Presence of Extra-Articular Deformity. Surg Tecnol Int 2019;15;34:497-502. Crossref

22. Kircher GJ, Lieber AM, Haislup B, Kerbel YE, Moretti VM. The Cost of Robot-assisted Total Hip Arthroplasty: Comparing Safety and Hospital Charges to Conventional Total Hip Arthroplasty. J Am Acad Orthop Surg 2021;29(14):609-15. Crossref 